\title{
Effect of a fruit and vegetable intervention on subjective mood and mental health in older adults
}

\author{
C. Rooney ${ }^{1}$, C. E. Neville ${ }^{1}$, I. S. Young ${ }^{1}$, S. E. C. M. Gilchrist ${ }^{1}$, M. C. McKinley ${ }^{1}$, A. Gibson ${ }^{1}$, \\ T. Banerjee ${ }^{2}$, J. D. Edgar ${ }^{3}$ and J. V. Woodside ${ }^{1}$ \\ ${ }^{1}$ Nutrition and Metabolism Research Group, Centre for Public Health, Queen's University Belfast, Belfast, BT12 6BJ, \\ ${ }^{2}$ Unilever R\&D, Colworth Science Park, Sharnbrook, Bedfordshire, MK44 ILQ, UK and ${ }^{3}$ Regional Immunology Service, \\ Belfast Health and Social Care Trust, Belfast, BT12 6BN, UK
}

Mental health problems are among the leading causes of disability worldwide ${ }^{(1)}$. Evidence shows that older adults are particularly vulnerable, with the risk of mental disorders such as depression increasing with age ${ }^{(2)}$. A growing body of research suggests that fruit and vegetables (FV) may have the potential to positively impact upon aspects of mental health including mood ${ }^{(3)}$. However, evidence to date is largely observational, and thus the present study aimed to examine the effect of increased FV consumption on subjective mood and mental health among healthy, free-living older adults.

Eighty-three participants (aged $\geq 65$ years), who were identified as low consumers of $\mathrm{FV}$ ( $\leq 2$ portions daily), were recruited to take part in a randomised controlled intervention study. Participants were randomised to one of two diets ( $\leq 2$ portions FV/day or $\geq 5$ portions FV/day) for a total of 16 weeks. FV were provided free of charge to participants on a weekly basis. Compliance was monitored by diet history and by measuring biomarkers of micronutrient status at baseline, 6 weeks, 12 weeks and 16 weeks. Mental health and mood was assessed at baseline and at 16 weeks using the validated General Health Questionnaire (GHQ-28) and a modified version of the validated Profile of Mood States (POMS) questionnaire respectively. Ethical approval for the study was obtained from the Office for Research Ethics Committees Northern Ireland (ORECNI).

Results from the study showed that, in terms of compliance, participants in the $\geq 5$ portions FV/day group had a significantly greater daily consumption of FV at week 16 compared to those in the $\leq 2$ portions FV/day group $(P<0.001)$. As shown in the table below, there was a general trend towards a greater reduction in GHQ-28 scores (indicative of better mental health) in the $\geq 5$ portions FV/day group compared to the $\leq 2$ portions FV/day group at week 16 , although these findings were not statistically significant. Similarly, there was no significant difference in change in total POMS scores between the groups.

\begin{tabular}{|c|c|c|c|c|c|c|c|c|c|}
\hline & \multicolumn{4}{|c|}{2 Portions/day $\left(n_{\max }=38\right)$} & \multicolumn{5}{|c|}{5 Portions/day $\left(n_{\max }=42\right)$} \\
\hline & \multicolumn{2}{|c|}{ Baseline } & \multicolumn{2}{|c|}{ Week 16} & \multicolumn{2}{|c|}{ Baseline } & \multicolumn{2}{|c|}{ Week 16} & \multirow[t]{2}{*}{$P^{\mathrm{b}}$} \\
\hline & Mean $^{a}$ & SD & Mean & SD & Mean $^{\mathrm{a}}$ & SD & Mean & SD & \\
\hline $\begin{array}{l}\text { GHQ-28 Total score } \\
\text { Subscales (scores) }\end{array}$ & 14.4 & 6.6 & 13.7 & 6.3 & 12.7 & 4.7 & 11 & 4.4 & 0.4 \\
\hline Somatic symptoms ${ }^{\mathrm{c}}$ & 3.7 & 3.4 & 3.5 & 2.8 & 2.9 & 2.5 & 2.3 & 1.8 & 0.6 \\
\hline Anxiety and insomnia ${ }^{c}$ & 3.3 & 2.7 & 3 & 2.8 & 2.7 & 2.6 & 2 & 2.2 & 0.4 \\
\hline Social dysfunction $^{\mathrm{c}}$ & 7.3 & 1.8 & 6.9 & 2.1 & 6.9 & 1 & 6.6 & 1.9 & 0.9 \\
\hline Depression $^{\mathrm{c}}$ & 0.2 & 0.7 & 0.4 & 1.2 & 0.2 & 0.6 & 0.1 & 0.3 & 0.2 \\
\hline POMS Total scored & -10 & 13 & -13 & 16 & -11 & 14 & -14 & 13 & 0.6 \\
\hline
\end{tabular}

${ }^{\mathrm{a} B a s e l i n e}$ values did not differ significantly between groups. Significance level was set at $P<0.05$ (independent samples t-test). ${ }^{\mathrm{b}} P$ value for change in scores (change calculated as baseline scores - week 16 scores) by group (independent samples t-tests for GHQ data and Mann-Whitney U test for POMS data). Significance level was set at $P$ 0.05. ${ }^{\mathrm{c}} \mathrm{GHQ}$ data are presented as mean \& standard deviation. ${ }^{\mathrm{d}}$ POMS data are presented as median \& interquartile range.

In conclusion, the present study did not observe any effect of a FV rich diet on mental health or mood.

1. Collins PY, Patel V, Joestl SS et al. (2011) Nature 475, 27-30.

2. Alexopoulos GS (2005) Lancet 365, 1961-1970.

3. Mamplekou E, Bountziouka V, Psaltopoulou T et al. (2010) J Nutr Health Aging 14, 449-455. 